\title{
HUBUNGAN KECERDASAN EMOSIONAL DENGAN PRESTASI BELAJAR MAHASISWA PENDIDIKAN TEKNIK ELEKTRO FAKULTAS TEKNIK UNIVERSITAS NEGERI
}

\author{
JAKARTA \\ ${ }^{1}$ Nur Aulia Rachmadini, ${ }^{2}$ Suyitno, ${ }^{3}$ Irzan Zakir. \\ 1,2,3 Pendidikan Teknik Elektro, Fakultas Teknik, Universitas Negeri Jakarta \\ 1,2,3 Email: rachmadini14@gmail.com; suyitno@unj.ac.id; irzan.zakir@unj.ac.id
}

\begin{abstract}
As purposes of this research are to know the level of emotional intelligence, learning achievement, and the closeness of the relationship of emotional intelligence and learning achievement of students. This research is an ex-post facto study and use a quantitative approach. The population of this research is students of Electrical Engineering Education, Faculty of Engineering, State Univerisity of Jakarta, years generation of 2015, 2016, and 2017, with a sample of 141. The analysis data techniques use descriptive statistical techniques and product moment correlation. The result of this research, showed that level of emotional intelligence and learning achievement of students had a good result with the result of $t_{\text {count }}$ variabel $X=-0,00634$ and the result of $t_{\text {count }}$ variabel $Y=0.940$ with $t_{\text {table }}= \pm 1,65581$. Then, the result of the analysis with product moment correlation obtained a value $r_{\text {count }}=0,331$, then that result are compared with $r_{\text {table }}=0,165$ with a significance level of $5 \%$ and $N=141$. Because $r_{\text {count }}>r_{\text {table }}$ then shows a positive and significant relationship between emotional intelligence and learning achievement of students.
\end{abstract}

Keyword: Emotional Intelligence, Students, Learning Achievement

\begin{abstract}
Abstrak
Penelitian ini bertujuan untuk mengetahui tingkat kecerdasan emosional dan prestasi belajar, dan keeratan hubungan antara kecerdasan emosional dengan prestasi belajar mahasiswa.

Penelitian ini merupakan penelitian ex-post facto dan menggunakan pendekatan kuantitatif. Populasi dalam penelitian ini adalah mahasiswa Pendidikan Teknik Elektro Fakultas Teknik Univeristas Negeri Jakarta angkatan tahun 2015, 2016, dan 2017 dengan sampel sebanyak 141. Teknik analisis data menggunakan teknik statistik deskriptif dan korelasi product moment.

Hasil penelitian ini, menunjukkan bahwa tingkat kecerdasan emosional dan prestasi belajar mahasiswa memiliki hasil yang baik dengan hasil $t_{\text {hitung }}$ variabel $\mathrm{X}=-0,00634$ dan hasil $\mathrm{t}_{\text {hitung }}$ variabel $\mathrm{Y}=0,940$ dengan $\mathrm{t}_{\text {tabel }}= \pm 1,65581$. Selanjutnya, hasil analisis dengan korelasi product moment diperoleh nilai $\mathrm{r}_{\text {hitung }}=0,331$ kemudian hasil tersebut dibandingkan dengan $r_{\text {tabel }}=0,165$ dengan taraf signifikansi 5\% dan $\mathrm{N}=141$. Karena $\mathrm{r}_{\text {hitung }}>_{\text {rtabel }}$ maka menunjukan hubungan yang positif dan signifikan antara kecerdasan emosional dengan prestasi belajar mahasiswa.
\end{abstract}

Kata kunci: Kecerdasan Emosional, mahasiswa, Prestasi Belajar.

\section{PENDAHULUAN}

Proses pendidikan di sekolah pada intinya adalah kegiatan belajar mengajar. Perbaikan dan peningkatan proses kegiatan belajar mengajar menjadi perhatian bagi pengelola pendidikan. Suatu upaya dalam meningkatkan proses belajar mengajar di sekolah dapat dilakukan dengan meninjau komponen yang terlibat dalam kegiatan mengajar.

Belajar merupakan proses dasar dari perkembangan hidup manusia. Dengan belajar, manusia melakukan perubahan-perubahan kualitatif individu sehingga tingkah lakunya berkembang. Semua aktivitas dan prestasi hidup manusia tidak lain adalah hasil dari belajar.

Salah satu komponen utama dalam proses belajar mengajar ialah peserta didik. Peserta didik adalah suatu masukan (input) yang akan di proses sehingga akan menghasilkan produk (output) sebagaimana yang diharapkan. Melalui pengalaman belajar, peserta didik akan mengalami perubahan dari segi kognitif, afektif, dan psikomotor. Beberapa faktor yang mempengaruhi proses belajar mengajar pada peserta didik meliputi dua faktor yaitu, faktor internal dan faktor eksternal. Faktor eksternal terdiri dari faktor lingkungan (keluarga maupun sosial) dan faktor instrumental (kurikulum, program, sarana, fasilitas, dan guru). Faktor internal meliputi aspek fisiologis dan psikologis.

Dalam setiap proses belajar, pelajar akan mengalami perubahan, mulai dari tidak tahu menjadi tahu, tidak mengerti menjadi mengerti dan mendorong perubahan sikap yang mengarah kepada hal yang lebih positif. Hal ini dikaitkan dengan hasil belajar. Mendapatkan hasil belajar yang maksimal sangat tergantung pada proses belajar yang dijalani. Salah satu usaha yang digunakan untuk mewujudkan hasil belajar maksimal adalah dengan meningkatkan prestasi belajar peserta didik. 
Prestasi belajar merupakan tolak ukur yang utama untuk mengetahui keberhasilan belajar seseorang. Seseorang yang prestasinya tinggi dapat dikatakan bahwa ia telah berhasil dalam belajar. Menurut Marsun dan Martaniah dalam skripsi Amalia Sawitri Wahyuningsih (2004: 12) mengenai hubungan antara kercedasan emosional dengan prestasi belajar pada peserta didik kelas II SMU Lab School Jakarta Timur mengatakan bahwa "prestasi belajar merupakan hasil kegiatan belajar, yaitu sejauh mana peserta didik menguasai bahan pelajaran yang diajarkan, yang diikuti oleh munculnya perasaan puas bahwa ia telah melakukan sesuatu yang baik.". Hal ini berarti prestasi belajar hanya bisa diketahui jika telah dilakukan penilaian terhadap hasil belajar peserta didik.

Kenyataannya, pelajar seringkali tidak mampu mencapai tujuan belajarnya atau tidak memperoleh perubahan tingkah laku sebagaimana yang diharapkan. Sementara itu, setiap pelajar dalam mencapai prestasi belajar yang baik, mempunyai kemampuan yang berbeda-beda. Sehingga menimbulkan masalah bagi perkembangan pribadinya.

Setiap individu memang tidak ada yang sama. Perbedaan inilah yang menyebabkan perbedaan tingkah laku belajar di kalangan pelajar. Belajar memerlukan kesiapan rohani dan ketenangan dengan baik. Apabila di rinci, faktor rohani meliputi intelegensi, bakat, minat, motivasi, faktor kesehatan mental, dan tipe khusus seorang pelajar (Ahmadi, A, 2004:138). Selain itu, ditentukan juga oleh faktor-faktor kekuatan lain.

Menurut Goleman (2000:44) faktor kekuatan-kekuatan lain tersebut diantaranya adalah kecerdasan emosional atau Emotional Quotient (EQ) yakni, kemampuan memotivasi diri sendiri, mengatasi frustasi, mengontrol desakan hati, mengatur suasana hati (mood), berempati, serta kemampuan bekerja sama. Kecerdasan emosional menjadi suatu faktor penentu yang muncul untuk mencapai keberhasilan yang optimal dalam suatu proses pembelajaraan selain kecerdasan intelektual. Kecerdasan emosional dianggap sebagai penentu, pengelolaan emosional baik emosi positif dan emosi negatif menentukan seseorang mampu melalui proses pembelajaran dan mencapai hasil belajar yang maksimal.

Dalam jurnal hubungan antara kecerdasan emosional dengan hasil belajar keterampilan dasar sepak bola peserta didik, Ajeng Dian Purnamasari, menjelaskan bahwa dalam hasil penelitian di New York University (Center for Neural Science) mengenai analisis struktur neurologis otak manusia dan penelitian perilaku oleh Le Doux (Goleman, 2009: 17) mengatakan bahwa EQ selalu mendahului IQ. Pelajar yang mendapatkan nilai buruk dalam suatu mata pelajaran diakibatkan dia tidak menyukai sang guru, pelajar tersebut mengutamakan perasaannya terlebih dahulu, sehingga sang pelajar bermalas-malas dalam mempelajari mata pelajaran yang dapat mempengaruhi penguasaan materi.

Penguasaan materi pada tiap mata kuliah yang diampu akan mampu membentuk sikap positif terhadap mahasiswa. Sikap positif ini merupakan prasarat keberhasilan belajar dan meningkatnya minat mahasiswa terhadap pelajaran selanjutnya. Dengan kata lain, jika penguasaan materi pada tiap mata kuliah di kelas awal sangat rendah disertai dengan sikap negatif terhadap pelajaran tersebut, sulit diharapkan mahasiswa akan berhasil dengan baik dalam pembelajaran selanjutnya.

Di Prodi Pendidikan Teknik Elektro Universitas Negeri Jakarta, sebagian besar mahasiswa yang masuk ke program studi ini bukan karena inisiatif sendiri. Ada berbagai alasan mengapa mereka memilih program studi ini, seperti mengikuti perintah orang tua ataupun asal memilih. Oleh karena itu, Mahasiswa yang masuk di Prodi Pendidikan Teknik Elektro yang mayoritasnya adalah peserta didik dari SMA IPA yang memiliki prestasi cukup baik mengalami penurunan dalam prestasi belajar. Penurunan ini diduga karena keadaan emosi yang kurang baik, dengan kata lain kecerdasan emosi mereka tidak cukup baik.

Setelah melakukan observasi, hal ini terlihat pada kondisi saat pembelajaran ditiap angkatan dimana banyak mahasiswa yang kurang memiliki semangat belajar karena faktor-faktor tertentu, seperti kurangnya minat belajar pada beberapa mata kuliah karena menurut 
mahasiswa itu terlalu sulit, mahasiswa kurang menyukai dosen yang mengajar, ataupun kelelahan karena memiliki tugas lain. Sehingga mahasiswa mendapatkan prestasi belajar tidak cukup maksimal. Selain itu, banyak pula mahasiswa yang harus mengulang beberapa mata kuliah karena nilai yang mereka dapat di bawah standar seperti mendapatkan nilai C-, D, dan E. Serta, masih terdapat mahasiswa yang lulus lebih dari 8 semester. Hal ini dapat disebabkan oleh, diantaranya:

1. Mahasiswa kurang memperhatikan pembelajaran dosen di kelas.

2. Mahasiswa kurang memiliki kesadaran dalam belajar.

3. Mahasiswa sering bolos.

Berdasarkan pemaparan di atas, penulis sangat tertarik untuk melakukan penelitian lebih lanjut mengenai keterkaitannya kecerdasan emosional dengan prestasi belajar mahasiswa. Oleh karena itu, penulis mengangkat penelitian ini dengan judul "hubungan kecerdasan emosional dengan prestasi belajar mahapeserta didik Pendidikan Teknik Elektro Fakultas Teknik Universitas Negeri Jakarta" (studi kasus di Universitas Negeri Jakarta, Jakarta).

\section{METODE PENELITIAN}

Metode penelitian adalah metode yang digunakan dalam mengumpulkan data penelitian. Penelitian ini merupakan penelitian kuantitatif asosiatif. Data kuantitaif ini berbentuk angka-angka yang akan dianalisis dengan perhitungan korelasi. Penelitian korelasional ini bertujuan untuk mendeteksi sejauh mana variasi-variasi pada suatu faktor berkaitan dengan variasi-variasi pada satu atau lebih faktor lain berdasarkan pada koefisien korelasi.

Dengan uji prasyarat analisis menggunakan uji normalitas dan uji linieritas kemudian data dianalisis menggunakan uji hipotesis, uji-t dan uji $\mathrm{F}$ dengan taraf signifikansi 5\%.

\section{HASIL DAN PEMBAHASAN}

\section{Kecerdasan Emosional Mahasiswa Pendidikan Teknik Elektro}

Berdasarkan hasil pengujian hipotesis ini, diketahui nilai thitung $=-0,00634$ dengan derajat kebebasan sebesar 140 dan taraf signifikansi $\alpha=$ $5 \%$ dengan $\mathrm{t}_{\text {tabel }}=0,165581$. Dilihat dari kriteria pengujian yang digunakan, terlihat hasil pengujian tersebut menunjukkan $t_{\text {hitung }} \leq t_{\text {tabel }}$ maka $\mathrm{H}_{0}$ diterima dan $\mathrm{H}_{a}$ ditolak yang berarti tingkat kecerdasan emosional mahasiswa Pendidikan Teknik Elektro cukup tinggi.

\section{Prestasi Belajar Mahasiswa Pendidikan Teknik Elektro}

Berdasarkan hasil pengujian hipotesis ini, diketahui nilai $\mathrm{t}_{\text {hitung }}=0,940$ dengan derajat kebebasan sebesar 140 dan taraf signifikansi $\alpha=$ $5 \%$ dengan $\mathrm{t}_{\text {tabel }}=-0,165581$. Dilihat dari kriteria pengujian yang digunakan, terlihat hasil pengujian tersebut menunjukkan $t_{h i t u n g} \geq t_{t a b e l}$ maka $\mathrm{H}_{0}$ diterima dan $\mathrm{H}_{a}$ ditolak yang berarti tingkat prestasi belajar mahasiswa Pendidikan Teknik Elektro cukup baik.

\section{Hubungan Kecerdasan Emosional dengan Prestasi Belajar Mahasiswa Pendidikan Teknik Elektro}

Berdasarkan hasil pengujian hipotesis ini, diketahui nilai $\mathrm{r}_{\mathrm{xy}}=0,331$ dengan derajat kebebasan sebesar 139 dan taraf signifikansi $\alpha=$ $5 \%$ dengan $r_{\text {tabel }}=0,165$. Dilihat dari kriteria pengujian yang digunakan, terlihat hasil pengujian tersebut menunjukkan $r_{\text {hitung }}>r_{\text {tabel }}$ maka $\mathrm{H}_{0}$ ditolak dan $\mathrm{H}_{\mathrm{a}}$ diterima yang berarti terdapat hubungan yang positif antara kecerdasan emosional dengan prestasi belajar mahasiswa.

Hasil pengujian koefisien korelasi dengan taraf signifikansi $5 \%$ dan derajat kebebasan sebesar 139 didapatkan nilai $t_{\text {tabel }}$ sebesar 1,97718 dan thitung sebesar 4,13796, yang berarti $t_{\text {hitung }}>t_{\text {tabel }}$ maka dapat disimpulkan bahwa penelitian ini terdapat hubungan yang signifikan antara kecerdasan emosional dengan prestasi belajar mahasiswa

Berdasarkan hasil perhitungan uji hipotesis didapat nilai rxy sebesar 0,331 maka didapat koefisien determinasinya sebesar 0,1096 dibulatkan menjadi 0,11 . Hal ini berarti varians yang terjadi pada variabel kecerdasan emosional sebesar $11 \%$ yang mempengaruhi terhadap prestasi belajar dan sebesar $89 \%$ dipengaruhi oleh faktor lain. 
Tabel 1. Rangkuman Pengujian Hipotesis

\begin{tabular}{|c|c|c|c|c|c|}
\hline $\begin{array}{l}\text { Variabel } \\
\text { Penelitian }\end{array}$ & $\begin{array}{l}\mathbf{r} \\
\text { hitung }\end{array}$ & $\begin{array}{l}\text { t } \\
\text { hitung }\end{array}$ & $\begin{array}{l}\text { F } \\
\text { hitung }\end{array}$ & Ket. & $\begin{array}{l}\text { Keerata } \\
\mathrm{n} \\
\text { Hubung } \\
\text { an }\end{array}$ \\
\hline $\begin{array}{l}\text { Kecerdasan } \\
\text { emosional } \\
\text { mahasiswa } \\
\text { pendidikan } \\
\text { teknik elektro } \\
\text { (X) }\end{array}$ & - & $\begin{array}{l}- \\
0,00634\end{array}$ & - & $\begin{array}{l}\text { Cukup } \\
\text { Tinggi }\end{array}$ & \\
\hline $\begin{array}{l}\text { Prestasi } \\
\text { belajar } \\
\text { mahasiswa } \\
\text { pendidikan } \\
\text { teknik elektro } \\
\text { (Y) }\end{array}$ & - & 0,940 & - & $\begin{array}{l}\text { Cukup } \\
\text { Baik }\end{array}$ & \\
\hline $\begin{array}{l}\text { Kecerdasan } \\
\text { emosional } \\
(\mathrm{X}) \text { dengan } \\
\text { prestasi } \\
\text { belajar (Y) } \\
\text { mahasiswa } \\
\text { pendidikan } \\
\text { teknik elektro }\end{array}$ & $\mathbf{0 , 3 3 1}$ & 4,13796 & 0,838 & $\begin{array}{l}\text { Positif } \\
\text { dan } \\
\text { signifika } \\
\text { n }\end{array}$ & rendah \\
\hline
\end{tabular}

\section{KESIMPULAN DAN SARAN \\ Kesimpulan}

Berdasarkan hasil pengolahan data yang diperoleh dapat disimpulkan sebagai berikut:

1. Berdasarkan hasil pengujian hipotesis pertama, diketahui nilai thitung $=-0,00634$ dengan derajat kebebasan sebesar 140 dan taraf signifikansi $\alpha=5 \%$ dengan $t_{\text {tabel }}=$ 0,165581 . Dilihat dari kriteria pengujian yang digunakan, terlihat hasil pengujian tersebut menunjukkan $t_{\text {hitung }} \leq t_{\text {tabel }}$ maka $\mathrm{H}_{0}$ diterima dan $\mathrm{H}_{\mathrm{a}}$ ditolak yang berarti tingkat kecerdasan emosional mahasiswa Pendidikan Teknik Elektro cukup tinggi.

2. Berdasarkan hasil pengujian hipotesis kedua, diketahui nilai $t_{\text {hitung }}=0,940$ dengan derajat kebebasan sebesar 140 dan taraf signifikansi $\alpha=5 \%$ dengan $t_{\text {tabel }}=$ 0,165581 . Dilihat dari kriteria pengujian yang digunakan, terlihat hasil pengujian tersebut menunjukkan $t_{\text {hitung }} \geq \mathrm{t}_{\text {tabel }}$ maka $\mathrm{H}_{0}$ diterima dan $\mathrm{H}_{\mathrm{a}}$ ditolak yang berarti tingkat prestasi belajar mahasiswa Pendidikan Teknik Elektro cukup baik.
3. Berdasarkan hasil pengujian hipotesis ketiga, diketahui nilai $r_{x y}=0,331$ dengan derajat kebebasan sebesar 139 dan taraf signifikansi $\alpha=5 \%$ dengan $r_{\text {tabel }}=0,165$. Dilihat dari kriteria pengujian yang digunakan, terlihat hasil pengujian tersebut menunjukkan $\mathrm{r}_{\text {hitung }}>\mathrm{r}_{\text {tabel }}$ maka $\mathrm{H}_{0}$ ditolak dan $\mathrm{H}_{\mathrm{a}}$ diterima yang berarti terdapat hubungan yang positif antara kecerdasan emosional dengan prestasi belajar mahasiswa. Untuk nilai signifikansinya terbukti signifikan karena didapatkan nilai $t_{\text {tabel }}$ sebesar 1,97718 dan $t_{\text {hitung }}$ sebesar 4,13796 , yang berarti $t_{\text {hitung }}>t_{t a b e l}$, dengan nilai koefisien determinasi sebesar 0,11 $(11 \%)$.

\section{Saran}

Berdasarkan hasil penelitian yang didapat, kecerdasan emosional memiliki kaitan dengan prestasi belajar mahasiswa, maka dari itu peneliti memiliki saran sebagai berikut:

1. Kecerdasan emosional memiliki hubungan yang dengan prestasi belajar mahasiswa, oleh karena itu mahasiswa diharapkan mampu mengelola emosi yang mereka miliki dengan baik agar dapat memiliki prestasi yang baik.

2. Untuk Ketua Program Studi Pendidikan Teknik Elektro Fakultas Teknik Universitas Negeri Jakarta diharapkan untuk terus memberikan motivasi juga bimbingan terhadap mahasiswa nya melalui dosen Pembimbing akademik agar mahasiswa mampu menjaga prestasi belajarnya dalam kondisi apapun.

3. Untuk peneliti selanjutnya, diharapkan untuk dapat memasukan variabel lain yang berhubungan dengan prestasi belajar seperti motivasi belajar, lingkungan sosial, dan gaya belajar.

\section{DAFTAR PUSTAKA}

Agte, V.V. \& Chiplonkar, S.A. 2007. Linkage of Concepts of Good Nutrition in Yoga and Modern Science. Current Science. 92(7), 956-961

Ahmadi, Abu dan Supriyono, Widodo. 2004. Psikologi Belajar. Jakarta: Rineka Cipta 
Ajeng. 2013. Hubungan antara Kecerdasan Emosional dengan Hasil Belajar Keterampilan Dasar Sepakbola Siswa [Jurnal Skripsi]. Bandar Lampung(ID): Universitas Lampung

Goleman, Daniel. 2015. Kecerdasan Emosional. Hermaya T, Penerjemah. Jakarta (ID): PT. Gramedia Pustaka Utama. Terjemahan dari: Emotional Intelligence Goleman, Daniel. 2000. Working With Emotional Intelligence. Alex Tri Kantjono, Penerjemah. Jakarta (ID): PT. Gramedia Pustaka Utama

Goleman, Daniel. 2009. Emotional Intelligence (terjemahan). Jakarta: PT. Gramedia Pustaka Utama

Khodijah, Nyanyu. 2014. Psikologi Pendidikan. Jakarta: PT. RajaGrafindo Persada

Sawitri, Amalia. 2004. Hubungan antara Kecerdasan Emosional dengan Prestasi Belajar pada Siswa Kelas II SMU LAB. School Jakarta Timur [Skripsi]. Jakarta (ID). Universitas Persada Indonesia Y.A.I

Slameto. 2003. Belajar dan Faktor-faktor yang Mempengaruhi. Jakarta: Rineka Cipta

Subandi. 2011. Sabar: Sebuah Konsep Psikologi. Jurnal Psikologi. 38 (2): 215227

Syah, Muhibbin. 2007. Psikologi Pendidikan degan Pendekatan Baru. Bandung: Remaja Rosdakarya

Yap Leman. 2011. Hoki Intelligence. Jakarta: Gramedi 